\title{
An excised SV40 intron accumulates and is stable in Xenopus laevis oocytes
}

\author{
Tamar Michaeli, ${ }^{1}$ Zhen-Qiang Pan, and Carol Prives \\ Department of Biological Sciences, Columbia University, New York, New York 10027 USA
}

\begin{abstract}
Xenopus laevis oocytes injected with simian virus 40 (SV40) DNA synthesize abundant quantities of viral late region RNA. In a previous analysis of the $5^{\prime}$ ends of oocyte SV40 late RNAs, it was observed that, in contrast to the majority of the late RNA species, an abundant class of viral late RNAs, whose $5^{\prime}$ ends mapped at or near nucleotide 294, was not polyadenylated. The structure of this RNA class has now been characterized further. We have shown that this species consists of a class of small uncapped RNA molecules with heterogeneous 3 ' ends mapping between nucleotides 417 and 433 . This corresponds well with the position of a 139-nucleotide intron within the leader region of late 16S RNA (nucleotides 294-433). The identification of this RNA class as an excised intron was strongly supported by the fact that it displayed anomalous mobilities on different percentage polyacrylamide gels, a property of lariat introns. Furthermore, incubation of oocyte RNA with a HeLa cell extract with lariat debranching activity converted the small RNA to a class that now migrated as $\$ 140$ nucleotides in length in $8 \%$ gels, consistent with the size of the linear intraleader intron. Additional analysis of this RNA showed that it is primarily nuclear in localization and is probably the most stable viral RNA species in the oocyte. These data suggest that oocytes accumulate large quantities of the $16 \mathrm{~S}$ intraleader intron because of their failure to debranch this RNA efficiently.
\end{abstract}

[Key Words: RNA splicing; Xeopus laevis oocytes; SV40; stable intron]

Received March 29, 1988; revised version accepted June 23, 1988.

The study of SV40 gene expression has generated valuable models for the mechanisms regulating RNA polymerase II transcription and the processing pathways of its transcripts. The expression of the SV40 late transcription unit in infected monkey cells is very complex, containing multiple transcription initiation sites and an intricate splicing pattern (for review, see Lebowitz and Weissman 1970; Tooze 1981; Fried and Prives 1986). Readily detectable levels of viral late RNA are synthesized primarily in two types of cells: those that support the extrachromosomal replication of viral DNA, such as primate cell lines, and those into which large quantities of viral DNA have been introduced by microinjection (Mertz and Gurdon 1977; Graessman et al. 1978). Of the latter type, Xenopus laevis oocytes have provided the unique opportunity of being able to receive macromolecules such as nucleic acids or proteins simultaneously or sequentially into their nuclei or cytoplasm. Therefore, they have been utilized rather extensively for the analysis of SV40 expression, leading to several observations concerning similarities and dissimilarities between oocytes and infected monkey cells. Both cell types synthesize large quantities of late-region-specific RNA and proteins and lesser quantities of early-regionspecific RNA and proteins (DeRobertis and Mertz 1977; Rungger and Turler 1978; Fradin et al. 1982). However,

'Present address: Cold Spring Harbor Laboratory, Cold Spring Harbor, New York 11724 USA. it has been observed that the factors governing SV40 late RNA synthesis in injected oocytes are different from those operating in infected monkey cells (Miller et al. 1982; Michaeli and Prives 1985, 1987). Moreover, differences in the relative abundance of various viral transcripts between the two cell types exist, reflecting the efficiencies with which different splice sites are utilized (Wickens and Gurdon 1983; Fradin et al. 1984). Furthermore, it was shown previously that the $5^{\prime}$ ends of the SV40 late RNA synthesized in oocytes are extremely heterogeneous, even more so than those of infected monkey cells (Michaeli and Prives 1985). Of these multiple late RNAs, it was observed that a discrete and abundant subset was not polyadenylated (Michaeli and Prives 1985). We have carried out a series of experiments to identify further this nonpolyadenylated SV40 RNA species that accumulates in oocytes. Based on the results of these studies, we conclude that this RNA is an unusually stable nuclear intron that is excised from the leader region of the viral 16S RNA.

\section{Results}

\section{A late SV40 small RNA species is synthesized in oocytes}

We observed previously that the majority of the viral late RNAs whose different $5^{\prime}$ ends had been identified by S1 nuclease analysis were polyadenylated, but a subset 
of these transcripts with $5^{\prime}$ ends that were located in the vicinity of nucleotides 294-300 did not bind to oligo(dT)-cellulose. To gain insight into the apparent selective polyadenylation of late transcripts, we attempted to locate the $3^{\prime}$ ends of RNAs with $5^{\prime}$ ends in this region. RNA extracted from SV40-injected oocytes or infected monkey cells was hybridized to three different 3 '-endlabeled DNA probes and subjected to S1 nuclease analysis (Fig. 1). (1) NcoI probe: The 3'-labeled end of the NcoI probe (nucleotides 334-337) is located downstream of most of the initiation sites used in either monkey cells or oocytes and is therefore protected from S1 digestion by most late RNAs. Two major fragments were observed when oocyte RNA was analyzed. One was a full-length probe, protected by colinear transcripts. The other was a cluster of smaller fragments, the size of which map the $3^{\prime}$ ends of transcripts to the region between nucleotides 417 and 433 . The $3^{\prime}$ ends were not detected in either the polyadenylated RNA fraction (data not shown) or in control samples $\left(\mathrm{H}_{2} \mathrm{O}\right.$ injected). The analysis of infected monkey cell RNA indicated that the vast majority of the transcripts were colinear with the Ncol probe and that only very small quantities of transcripts with $3^{\prime}$ ends located between nucleotides 417 and 419 were present. (2) BanI probe: The $3^{\prime}$-labeled end of the BanI probe (nucleotides 295-298) should be protected from S1 digestion by all RNAs with $5^{\prime}$ ends mapping upstream of nucleotide 298. Indeed, infected monkey cell RNA, of which the most abundant major 5' end is located at nucleotide 325 (Ghosh et al. 1978; Gidoni et al. 1981), protected only a small fraction of this probe, in comparison to the S1-resistant fraction of the NcoI probe. In oocytes, the resistant fragments observed with the BanI probe corresponded to those detected with the NcoI probe, indicating that the $5^{\prime}$ ends of both the colinear transcripts and those with $3^{\prime}$ ends between nucleotides 417 and 433 lie upstream of nucleotide 298. (3) DdeI probe: The protection of the 3 '-labeled end of the DdeI probe by oocyte RNA (nucleotides 288-290) was dramatically different compared to the two other labeled
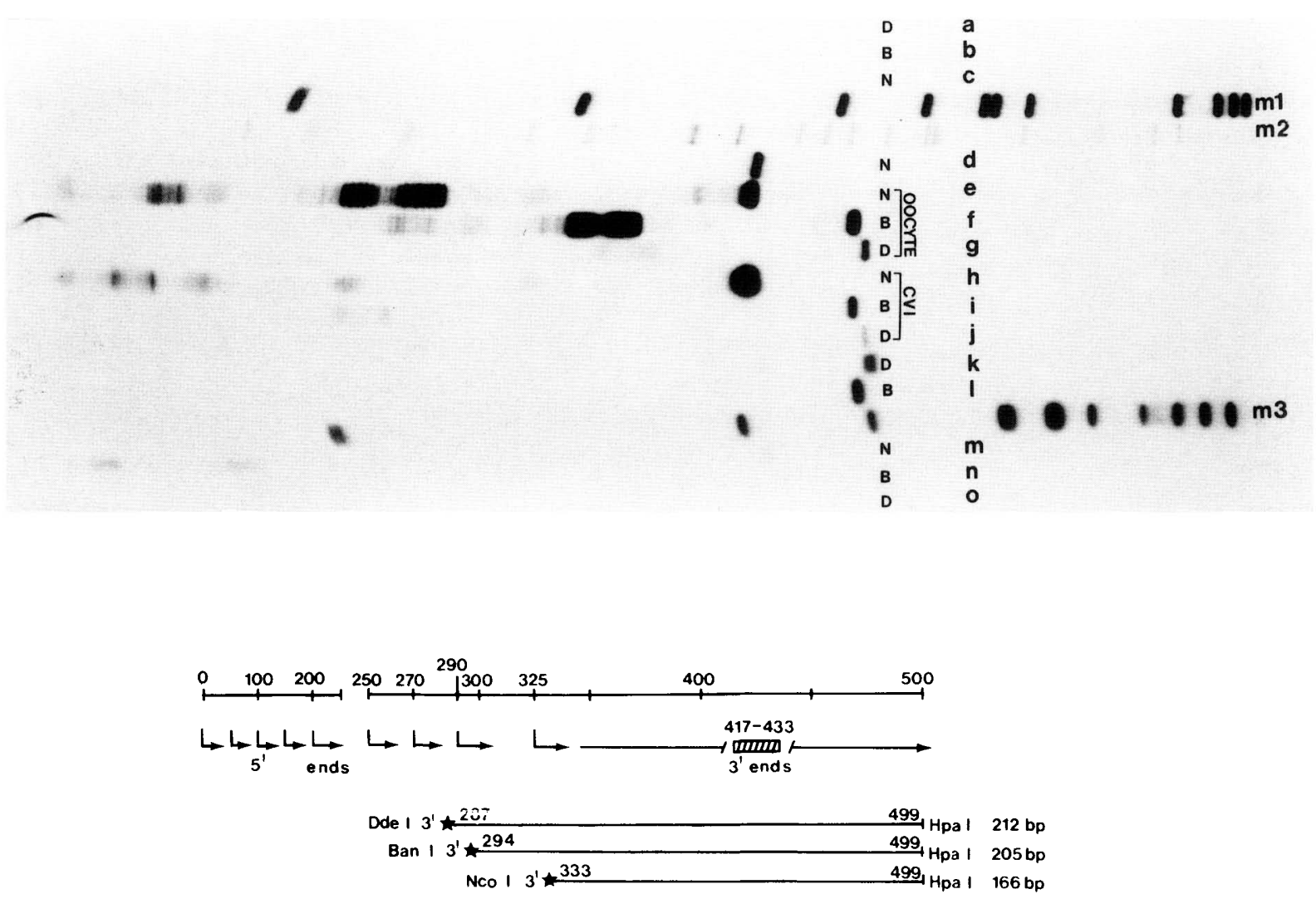

Figure 1. Sl nuclease mapping of the $5^{\prime}$ and $3^{\prime}$ ends of a small RNA species. Viral RNA extracted from SV40-injected oocytes $(e-g)$ and from infected CV-1 monkey cells $(h-j)$, and as controls RNA extracted from uninjected oocytes $(a-c)$ and uninfected CV-1 cells $(m-O)$ were mapped by $\mathrm{S} 1$ analysis. Three 3 '-end-labeled DNA probes were hybridized to the RNA samples: $N c o I(N)$ probe $(c, e, h, m)$, BanI (B) probe $(b, f, i, n)$, and DdeI (D) probe $(a, g, j, o)$. One-twentieth the amount of probe used in analysis is depicted for the $N c o I(d)$ BanI (l), and DdeI (k) probes. (Lane m1) Molecular-weight markers are the fragments generated by the HaeIII cleavage of X174 DNA and, from the top, are 1353,1078, 872,603,310,278,271,234, 194, 118, and 72 nucleotides in length; (lane m2) the fragments generated by the HpaII cleavage of pBR322 DNA and, from the top, are 622, 527, 404, 309, 242, 238, 217, 201, 190, 180, 160, 147, 123, $110,90,76,67,34,25$, and 9 nucleotides in length; (lane $m 3$ ) the fragments generated by the HincII cleavage of $\phi X 174$ DNA and, from the top, are $1057,770,612,495,392,345,341,335,297,291,210,162$, and 79 nucleotides in length. A diagram of the approximate location of late RNA 5' ends and of the mapped 3' ends is shown below the autoradiogram, as well as the DNA probes used in the analysis. 
probes. Although RNA colinear with the probe was observed in injected oocytes, the transcripts with $3^{\prime}$ ends between nucleotides 417 and 433 were barely detectable. Moreover, the S1 nuclease-resistant fraction of lytic RNA that hybridized to the $3^{\prime}$ end of this probe was reduced further, most likely reflecting the loss of protection by transcripts initiated at nucleotide 290 . Thus, a strong correlation between $5^{\prime}$ and $3^{\prime}$ ends of injected oocyte RNA can be deduced. RNAs with $5^{\prime}$ ends between nucleotides in the vicinity of nucleotide 294 most likely possess $3^{\prime}$ ends between nucleotides 417 and 433. The vast majority of other oocyte RNA species do not contain $3^{\prime}$ ends at this site. Thus, the analysis of $5^{\prime}$ and $3^{\prime}$ ends indicates the presence of an abundant nonpolyadenylated small RNA species, 122-143 nucleotides in length, in oocytes but not in infected monkey cells. This is consistent with previous observations of a small late SV40 RNA species in oocytes (Miller et al. 1982; Wickens and Gurdon 1983).

\section{Capped 5' ends of SV40 late RNA in oocytes}

It has been proposed (Hay et al. 1982) that the SV40 late region contains a regulated terminator in which small transcripts are generated with 3 ' ends within a uridinerich region preceded by a potential stem-loop RNA structure within the vicinity of nucleotide 435 . It was suggested that these small RNAs might be generated as a result of RNA polymerase attenuation in a manner analogous to that described for many prokaryotic systems. Although the identification of a class of small SV40 RNA in oocytes with $3^{\prime}$ ends in this region was intriguing, only RNAs with $5^{\prime}$ ends at or near nucleotide 294, but not RNAs mapping upstream of this region, terminated within nucleotides 417 and 433 . This suggested either that sequences at the $5^{\prime}$ ends of this RNA somehow caused termination within this region or that the small RNA was generated by an alternative route. To pursue this question further, we attempted to determine whether the $5^{\prime}$ ends at approximately nucleotide 294 are generated by transcription initiation.

The increased heterogeneity of late RNA $5^{\prime}$ ends observed in oocytes (Michaeli and Prives 1985) may be the product of transcription initiation or of additional processing events. Although transcription initiation yields capped $5^{\prime}$ termini, the $5^{\prime}$ ends of RNA generated by cleavage from larger transcripts would not likely be capped. To determine which of the late RNA 5 ' ends are capped, and thereby perhaps to gain insight into the stability and origin of the small RNA species, we immunoprecipitated oocyte RNA with antibodies that recognize the $\mathrm{Me}^{7} \mathrm{G}$ structure found in capped termini (Bringman et al. 1983). RNA before or after immunoprecipitation with anti-Me ${ }^{7} \mathrm{G}$ antibodies (Fig. 2A), or RNA that did not bind to the antisera (Fig. $2 \mathrm{~B}$ ) was extracted and subjected to a $5^{\prime}$-end analysis. The majority of the $5^{\prime}$ ends of injected oocyte SV40 late RNA were immunoprecipitated, although the most upstream species, and particularly those that protected the entire probe, were not bound to the antibodies as efficiently. However, in contrast to most of the RNAs, the small RNA species at approximately nucleotide 294 (Fig. 2, open arrow) did not interact with the antibodies, appearing in the unbound fraction exclusively. These antibodies have been shown to precipitate small RNA species such as snRNAs efficiently (Bringmann et al. 1983), making it unlikely that the size of the small SV40 RNA class prohibited their binding to the antibody. Although the immunoprecipitation of late lytic RNA from monkey cells was not completely quantitative, all of the $5^{\prime}$ ends that are known to be capped were recognized by the antibodies. In addition, $\mathrm{Me}^{7} \mathrm{G}$ added to the immunoprecipitation reaction inhibited recognition of all the $5^{\prime}$ ends of the two cell types (data not shown). These data confirmed and extended earlier studies (Gidoni et al. 1981) identifying capped SV40 late RNAs, and indicated that the majority of SV40 late RNA $5^{\prime}$ ends synthesized in oocytes are also capped, with the exception of those located at approximately nucleotide 294 . The absence of any detectable capped RNA initiating at or near nucleotide 294 strongly suggested that this species is homogeneous with respect to its $5^{\prime}$ terminus and also that it is not likely to result from regulated transcription termination.

\section{The small RNA species is an excised intron}

The observation that the small RNA was not immunoprecipitated by anti-Me ${ }^{7} \mathrm{G}$ antibodies, in contrast to the majority of the other SV40 late RNAs, led to the possibility that it was generated by cleavage from a larger RNA species. Thus, either endonucleolytic cleavage of late RNA resulting in an RNA species akin to the SV40 associated small RNA previously described (Alwine 1982) or the excision of an intron from late pre-mRNA could explain the presence of the small, uncapped RNA species in oocytes. Support for the latter possibility came from the correspondence of the map positions of the 16S mRNA intraleader intron splice sites (nucleotides 294-434), shown previously to be utilized in infected monkey cells (Reddy et al. 1978), with those of the oocyte small RNA whose $5^{\prime}$ end(s) mapped between nucleotides 290 and 295 and whose $3^{\prime}$ ends were located between nucleotides 417 and 433 . To test this, analyses were performed that have been shown previously to identify unusual RNA structures (Figs. 3A,B).

RNAs possessing circular or branched circular (lariat) structures migrate anomalously on polyacrylamide gels (Grabowski et al. 1984; Ruskin et al. 1984). Therefore, we analyzed the relative migration of the small late RNA with respect to DNA fragment markers after electrophoresis in $5 \%$ and $8 \%$ polyacrylamide $8 \mathrm{~m}$ urea gels (Fig. 3A). After transfer of the gels to nylon membranes under conditions that favor the transfer of smaller RNAs (Zeitlin and Efstratiadis 1984), the blots were hybridized to a ${ }^{32}$ P-labeled SV40 DNA probe spanning the region between nucleotides 294 and 499 . The predominant RNA species (large closed arrows) migrated to a position between those of 147- and 160-bp DNA fragments in the $5 \%$ gel but migrated only slightly more rapidly than a 242 -bp DNA fragment in an $8 \%$ polyacrylamide gel. Vir- 


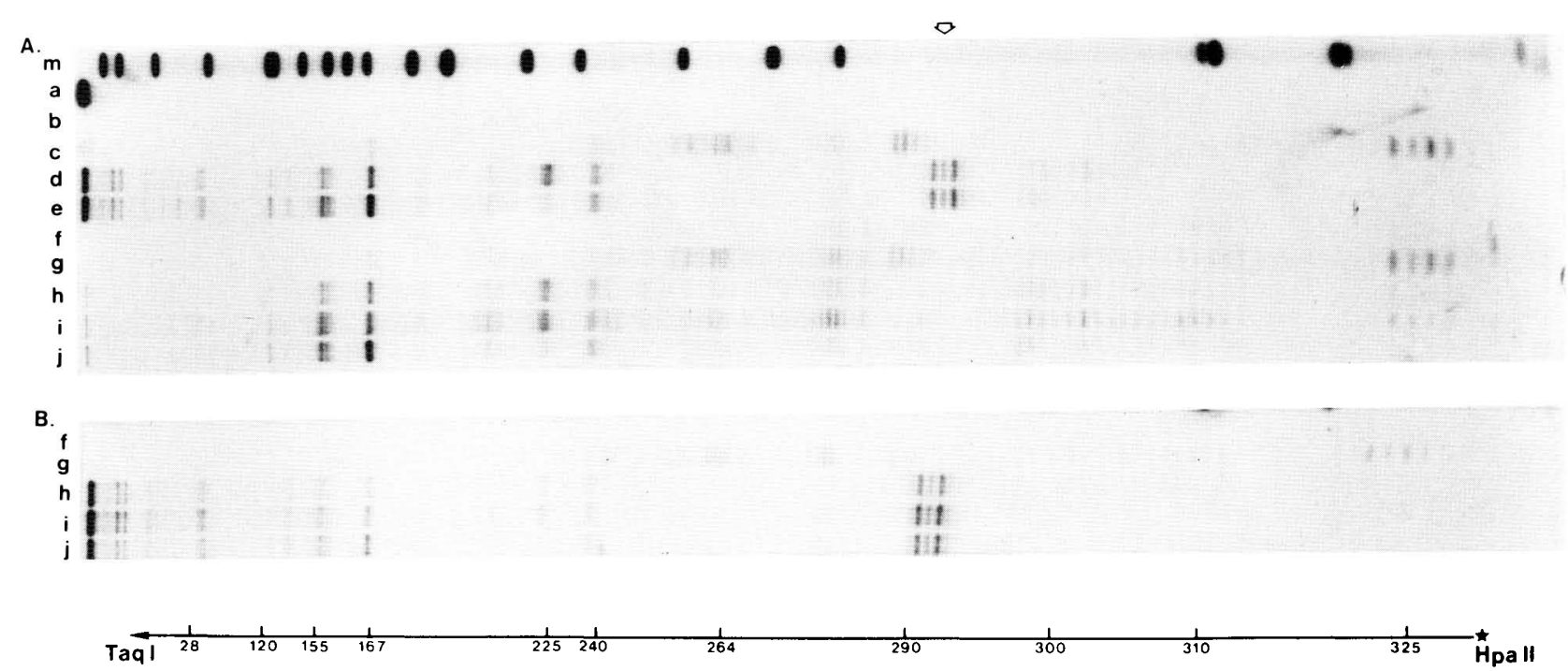

Figure 2. Immunoprecipitation of the capped $5^{\prime}$ termini of SV40 late RNA. RNA extracted from SV40-injected oocytes, infected $\mathrm{CV}-1$ cells, and control uninjected oocytes was immunoprecipitated with anit-Me ${ }^{7} \mathrm{G}$ antibodies as described in the text. Following immunoprecipitation, the $5^{\prime}$ ends of the bound $(A$, lanes $f-i)$ and unbound $(B)$ fractions of these RNA samples, as well as the RNA samples prior to their immunoprecipitation $(b-e)$, were mapped by $\mathrm{S} 1$ analysis with the $5^{\prime}$-labeled single-stranded HpaII-TaqI DNA fragment as described in the text and the legend to Fig. 2. The fragments protected from S1 digestion by uninjected oocyte RNA $(b, f)$, SV40-infected cells RNA $(c, g)$, SV40-injected oocyte RNA $(d, h)$, twice the amount of RNA of the same SV40-injected oocytes (i), and SV40-injected oocyte RNA from a different frog $(e, i)$ are shown. One-tenth the amount of probe used in analysis is depicted in $a$. Molecular-weight markers $(\mathrm{m})$ are the fragments generated by the HpaII cleavage of pBR322 described in the legend to Fig. 1. The open arrow indicates the position of the small late RNA with $5^{\prime}$ ends at or near nucleotide 294 . A diagram of the DNA probe with the approximate positions of major $5^{\prime}$ ends in monkey cells and oocytes is shown below the autoradiogram.

tually no RNA was detected at the 147- to 160-nucleotide positions in $8 \%$ polyacrylamide gels. Furthermore, significant quantities of RNA corresponding to the expected size of the linear $16 \mathrm{~S}$ intraleader intron species ( $\leqslant 140$ nucleotides) were not detected in either case. This result is similar to related observations of differential relative electrophoretic mobilities of lariat-form RNA introns in different concentrations of polyacrylamide. This major SV40 small RNA class was somewhat heterogeneous in both $5 \%$ and $8 \%$ gels, which is consistent with the existence of multiple $3^{\prime}$ ends of the small RNA, as shown in Figure 1. This may be due to an exonucleolytic activity that has been shown to remove the intron lariat tail in vitro (Ruskin and Green 1985).

To provide further support for the possibility that the small SV40 RNA species has a branched circular structure, RNA from microinjected oocytes was treated with a HeLa S-100 cell extract containing a debranching activity (Ruskin and Green 1985) (Fig. 3B). This extract had been shown to debranch excised introns efficiently from both SV40 large $\mathrm{T}$ antigen and adenovirus pre-mRNA isolated from in vitro splicing reactions (Noble et al. 1987). Indeed, confirming the results of these workers, after the debranching reaction, ${ }^{32} \mathrm{P}$-labeled gel-purified SV40 large T lariat-form intron was converted efficiently from a species migrating much more slowly than the 602-bp marker (Fig. 3B, small closed arrow) to one consistent with its size as a linear intron, i.e., 347 nucleotides (small open arrow). Similarly, the oocyte SV40 small RNA was converted efficiently to forms that mi- grated on $8 \%$ gels according to their expected size as linear species, i.e., 130-140 nucleotides (large open arrow). These analyses indicated that the SV40 small RNA has properties consistent with that of a branched or circular RNA and furthermore, that the majority of the stable small RNA exists as this structure, rather than as its linear form. Additional support for the notion that the small RNA species is a product of RNA splicing was obtained from experiments in which oligonucleotide-targeted degradation of U1 RNA in oocytes led to both the inhibition of SV40 late pre-mRNA splicing and the virtual complete disappearance of the small RNA species (Z. Pan and C. Prives, unpubl.). It is noteworthy that neither of the analyses in Figure 3, A and B, revealed other major classes of small RNAs. Although the major form of stable viral mRNA in oocytes is of the 19S type, both 19S introns (nucleotides 294-558 and 373-558), which would also hybridize to the probe utilized, were not detected by Northern analysis before or after debranching.

Cellular localization and relative stability of the small RNA

Wickens and Gurdon (1983) observed that the majority of SV40 late RNAs are found in the nuclei of injected oocytes and that only transcripts with mature $3^{\prime}$ ends, identical to those of late lytic mRNAs in their cleavage site and in their polyadenylation, are transported to the oocyte cytoplasm. Although the $3^{\prime}$ ends of the small 
A

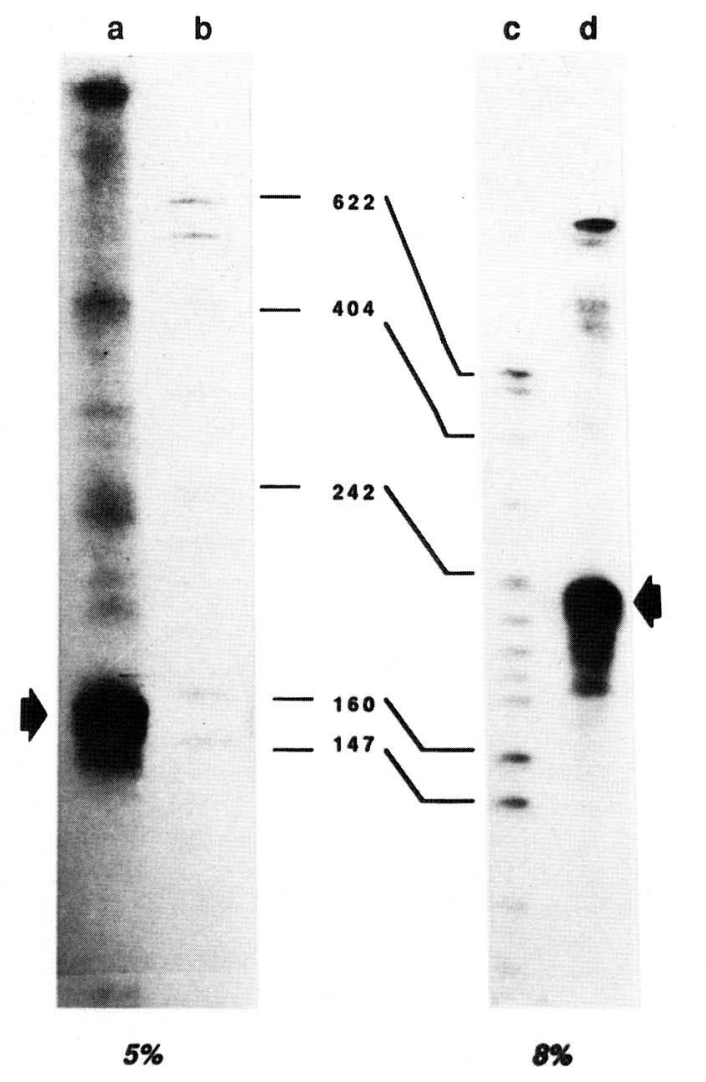

B

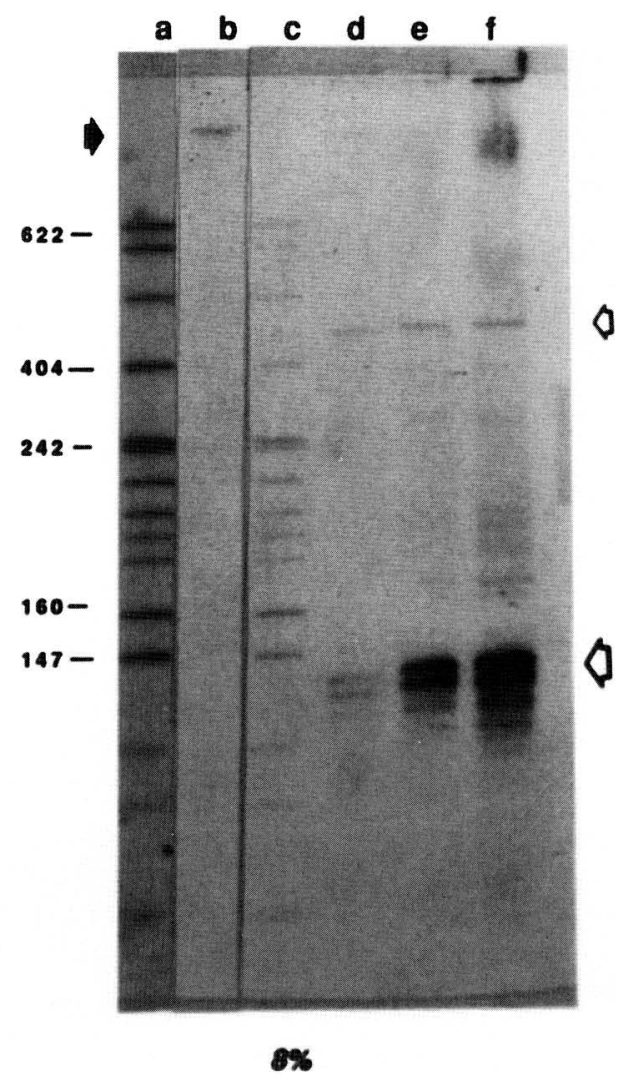

Figure 3. Electrophoretic mobilities of small SV40 RNA species synthesized in oocytes in different polyacrylamide gels before and after debranching. (A) RNA extracted from oocytes microinjected with $2.5 \mathrm{ng}$ SV40 DNA was subject to electrophoresis on either a $5 \%$ polyacrylamide gel (lane $a$ ), along with $10 \mathrm{ng}$ of ${ }^{32}$ P-labeled MspI pBR322 DNA fragments (lane $b$ ) whose size in nucleotide pairs are indicated, or on an $8 \%$ polyacrylamide gel (lane $d$ ) also in the presence of the same ${ }^{32}$ P-labeled DNA fragments (lane $c$ ). Gels were transferred to nylon filters, as described in Methods, and hybridized to a ${ }^{32} \mathrm{P}$-labeled KpnI-HpaI fragment that spans SV40 sequences between nucleotides 294 and 499 . Closed arrows point to the major species of RNA with altered relative mobility. $(B)$ RNA from 0.1 $(d), 0.35(e)$, or $0.7(f)$ oocytes, which had been injected with $2.5 \mathrm{ng}$ SV40 DNA $24 \mathrm{hr}$ prior to extraction was incubated with HeLa S-100 debranching extract in the presence of $0.1 \mathrm{ng}$ of ${ }^{32} \mathrm{P}$-labeled SV40 large T-antigen lariat-form intron (small open arrow), and subjected to electrophoresis in $8 \%$ polyacrylamide gels. Northern blotting analysis, using the same probe described in $A$, was performed to detect the SV40 small RNA species (large open arrow). By comparison, lane $b$ contains the ${ }^{32}$-labeled SV40 T-antigen lariat form intron before debranching (solid arrow), and lanes $a$ and $c$ contain the same ${ }^{32}$ P-labeled DNA fragment markers as in $A$. Note that there is no SV40 RNA detected at the position of the linear species $(\leqslant 140 \mathrm{nts})$ on $8 \%$ gels before debranching $(A$, lane $d)$ and, conversely, that virtually none of the major RNA species near the 242 position remains after debranching $(B$, lanes $d-f)$.

transcripts characterized were not polyadenylated, its small size might facilitate its transport or leakage into the cytoplasm. Therefore, it was of interest to determine the subcellular localization of the small RNAs. For this purpose, the distribution of the small RNA species between the two compartments was examined by manual separation of nuclei and cytoplasm (Fig. 4). RNAs extracted from these cell fractions were hybridized to a $3^{\prime}$ end-labeled NcoI-HpaI fragment, followed by $\mathrm{S} 1 \mathrm{nu}-$ clease digestion. Separation of the S1 nuclease-protected fragments on $5 \%$ polyacrylamide-urea gels allowed an assessment of the relative proportions of the small RNA to the larger late RNA classes. The results of this determination indicated that the majority of the small RNA was nuclear. In addition, a large portion of the RNAs colinear with the probe were nuclear as well. That extensive leakage of various small RNA species into the cytoplasm did not occur during the manual separation was indicated using internal controls in which distribution of a mixture of ${ }^{32} \mathrm{P}$-labeled HeLa cell small nuclear RNAs (snRNAs), 5S RNA, and tRNA after injection into oocytes was followed. Confirming experiments described previously by DeRobertis et al. (1982), it was shown that snRNAs injected into oocyte nuclei remain predominately in the nucleus, whereas 5S RNA and tRNAs accumulate exclusively in the cytoplasm (Fig. 4).

The small RNA intron by $5^{\prime}$-end mapping appeared to be one of the more abundant classes of late RNAs in oocytes (Michaeli and Prives 1985). Therefore, the quantities and stability of this RNA were analyzed relative to the other late RNAs in oocytes. RNA was extracted from oocytes at different times after injection and characterized by hybridization to a 3 '-end-labeled NcoIHpaI probe followed by $\mathrm{S} 1$ nuclease digestion. As seen in 


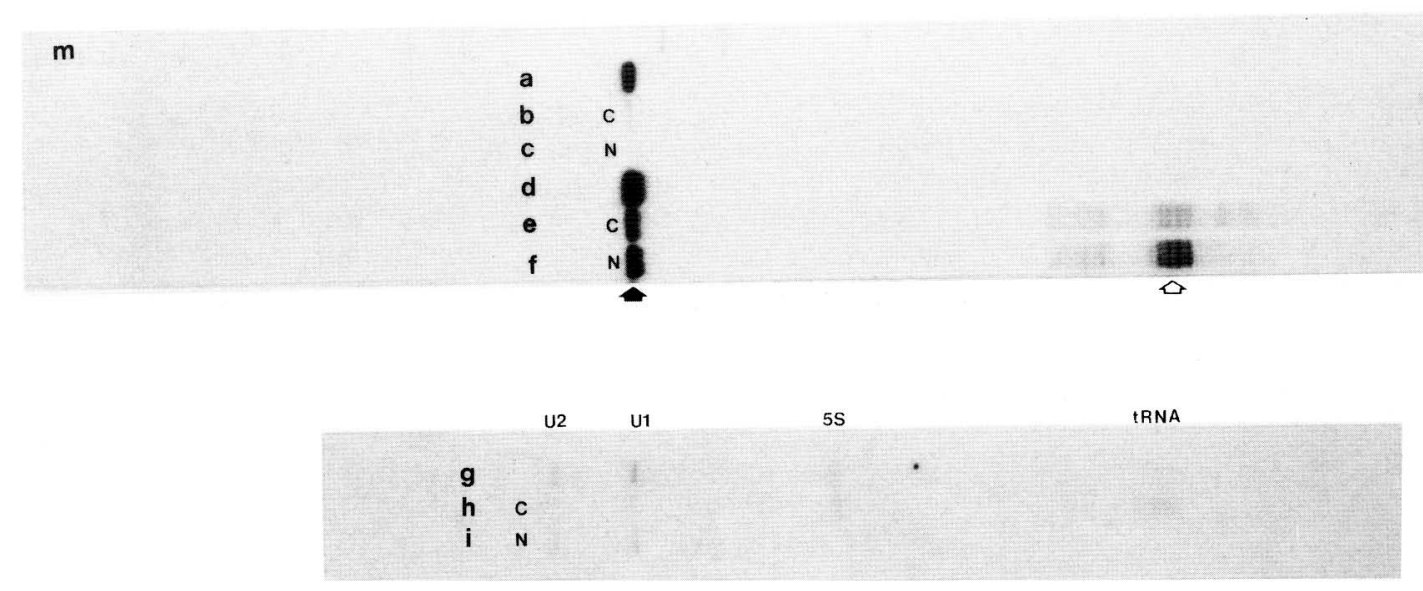

Figure 4. Nuclear and cytoplasmic distribution of some of the 3' ends of SV40 late RNAs in oocytes. Oocytes were injected intranuclearly with $2.5 \mathrm{ng}$ of SV40 DNA I along with ${ }^{32}$-labeled snRNAs, 5S RNA, and tRNAs isolated from HeLa cells. (C) Cytoplasm; (N) nucleus. The cytoplasm $(e)$ and nuclei $(f)$ of the injected oocytes were separated manually, and aliquots of the RNA extracted from the two fractions were hybridized to the same 3'-labeled NcoI-HpaI fragment used in Fig. 3. Following S1 nuclease digestion, the resistant fragments were separated on a $5 \%$ polyacrylamide-urea gel. RNA extracted from uninjected oocyte cytoplasm $(b)$ and nuclei $(c)$ and from SV40-infected cells $(d)$ were analyzed as well. The location of RNAs colinear with the probe is indicated by a solid arrow, and that of the $3^{\prime}$ ends, by an open arrow. One-twentieth the amount of probe used in analysis is depicted in lane $a$. Aliquots of total injected oocyte RNA $|g|$, cytoplasmic $(h)$, and nuclear (i) fractions were electrophoresed in parallel, and the location of the ${ }^{32} \mathrm{P}-\mathrm{labeled}$ HeLa cell small RNAs (U1 and U2 snRNAs), 5S RNA, and tRNAs are indicated. Molecular-weight (m) markers are the fragments generated by the HpaII cleavage of PBR322, described in the legend to Fig. 2.

Figure 5, quantities of both probe-length (or greater) RNAs, as well as the small RNA intron class, accumulate with increasing time intervals after injection. At earlier times there are relatively greater quantities of the larger species (Fig. 5, lanes e-g), whereas at later times (24-48 $\mathrm{hr}$ postinjection), there are greater quantities of the smaller RNA (lanes $h$ and i). To determine the relative stability of large or small late RNAs, oocytes were injected with $\alpha$-amanitin $6 \mathrm{hr}$ prior to extraction and S1 analysis (Fig. 5, lanes $j$ and $\mathrm{k}$ ). The results of this experiment showed a marked difference in the relative stability of the smaller and larger RNAs such that the majority of the latter was no longer present after $6 \mathrm{hr}$ in the presence of $\alpha$-amanitin, where equal or greater quantities of the intron species were present at that point. A similar result was obtained when the $\alpha$-amanitin chase was performed from 24-48 hr following injection (not shown). Thus, the small 16S intraleader RNA intron is a predominantly nuclear RNA that possesses unusual stability when compared to other late SV40 RNAs synthesized in X. laevis oocytes.

\section{Discussion}

We have characterized an abundant and stable class of SV40 RNA that accumulates in X. laevis oocytes, whose properties are consistent with its identification as an excised lariat-form intron: (1) Its 5' and 3' ends correspond to those of an intron located within the leader portion of 16S RNA, mapping between nucleotides 294 and 435 on the viral genome; $(2)$ it is neither capped nor polyadenylated; (3) it exhibits anomalous mobilities in different polyacrylamide gels; (4) it is converted to a size class consistent with the linear intron after debranching; and $(5)$ it is predominantly nuclear in localization. Related to these observations, another group has observed that mutations affecting the $5^{\prime}$ - or $3^{\prime}$-splice sites of the $16 \mathrm{~S}$ intraleader intron led to the disappearance of the small RNA in oocytes (J. Mertz, pers. comm.). Our experiments indicate that this small RNA does not accumulate to comparable levels in SV40-infected monkey cells as observed in oocytes. However, because only $10 \%$ of the $16 \mathrm{~S}$ spliced mRNAs in infected monkey cells have been shown to have formed the intraleader splice (Reddy et al. 1979), it is difficult to assess whether this is a direct or indirect effect.

The accumulation of the excised intron appears not to be a general property of other SV40 introns in oocytes. The Northern analyses shown in Figure 3 would very likely have detected other stable small RNAs such as other introns from this region, if they were present in comparable quantities. As seen in Figure 3, under conditions in which the abundant intraleader intron was efficiently debranched, only one major size class of RNA (130-139 nucleotides) was detected. In contrast, major species $\$ 185$ nucleotides (linear form of the 373 - to 558 nucleotide 19S intron) or of $\$ 264$ nucleotides (linear form of the 294- to 558-nucleotide $19 \mathrm{~S}$ intron) were not present in detectable quantities relative to the amount of the $\$ 139$-nucleotides linear form of the intraleader intron. As 19S spliced RNA is a major stable mRNA species found in oocytes, the lack of detection of either of its two possible introns strongly suggests that the accumulation of the intraleader $16 \mathrm{~S}$ intron is not common to all viral RNAs in oocytes but may be related to the sequences that are unique to this intron. 
As virtually all of the $16 \mathrm{~S}$ intraleader RNA exists as an anomalously migrating species in $8 \%$ gels before but not after debranching, it most likely accumulates almost entirely as a lariat rather than a linear RNA. Its stability may well be related to this structure, and this may result from its failure to be debranched. To our knowledge, debranching activity from $X$. laevis oocytes has not yet been identified or characterized. Although the debranching activity in extracts (Kramer and Keller 1985; Ruskin and Green 1985) or more purified preparations (Arenas and Hurwitz 1987) from HeLa cells has been characterized, little is known about the specificity of its requirements, if any, for the sequences surrounding the branchpoint. Evidence for the existence of factors such as small nuclear ribonucleoproteins (snRNPs) within splicing extracts that inhibit the activity of the debranching enzyme, possibly by protection of the precursor RNA, has been published (Ruskin and Green 1985; Arenas and Hurwitz 1987). The intraleader intron may possess unique features that increase its affinity for such factors.

Elucidation of the mechanism of splicing and of the structure of introns has progressed largely through the analysis of RNA-processing products from in vitro systems. However, cellular RNAs from higher eukaryotes corresponding in size and sequence to introns removed from $\beta$-globin (Zeitlin and Efstratiadis 1984) and immunoglobulin (Coleclough and Wood 1984) premRNAs have been described. The existence of branched RNA structures was first described in nuclear RNA by Wallace and Edmonds (1983), who postulated that they may be RNA-processing intermediates. Identification of yeast (Domdey et al. 1984; Rodriguez et al. 1984), $\beta$ globin (Zeitlin and Efstratiadis 1984), and SV40 large tumor antigen (Noble et al. 1987) introns from intact cells existing in circular or lariat form was subsequently reported. However, these studies provided no evidence for the stability or accumulation of these introns relative to other introns of a given transcription unit, or to the mature mRNA product. Our studies suggest that, in at least one cell type - the X. laevis oocyte- one intron, but not others, can accumulate primarily in the nucleus. The fact that this RNA is almost entirely in circular or lariat form may be related to its relative abundance. Studies are planned to determine which sequences within this intron are responsible for its unusual stability.

\section{Methods}

Materials

SV40 DNA I was purchased from Bethesda Research Laboratories. X. laevis mature females were obtained from Nasco. Affinity-purified anti-Me $\mathrm{Me}^{7} \mathrm{G}$ antibodies were a generous gift from R. Luhrmann. Restriction enzymes and the large fragment of DNA polymerase were purchased from New England Biolabs. DNase I, proteinase $\mathrm{K}, \mathrm{T} 4$ polynucleotide kinase, and $\alpha$-amanitin were obtained from Boehringer-Mannheim. Radioactive isotopes were purchased from the Radiochemical Center, Amersham. RNasin was obtained from Promega Biotech. GeneScreen Plus membrane filters were bought from New England Nuclear Products, and protein A-Sepharose was obtained from Pharmacia.

\section{Injection into oocyte nuclei}

Preparation and maintenance of oocytes, as well as microinjection into oocyte nuclei, were performed as described (Michaeli and Prives 1985). Oocytes were microinjected with $2.5 \mathrm{ng} \mathrm{SV} 40$ DNA I and were usually incubated for a 48 -hr period. $\alpha$-Amanitin was either injected along with the DNA or following an initial incubation period. snRNAs, 5S RNA, and tRNAs labeled with ${ }^{32} \mathrm{P}$ were prepared from HeLa cells according to published procedures (Lerner and Steitz 1979), were coinjected with SV40
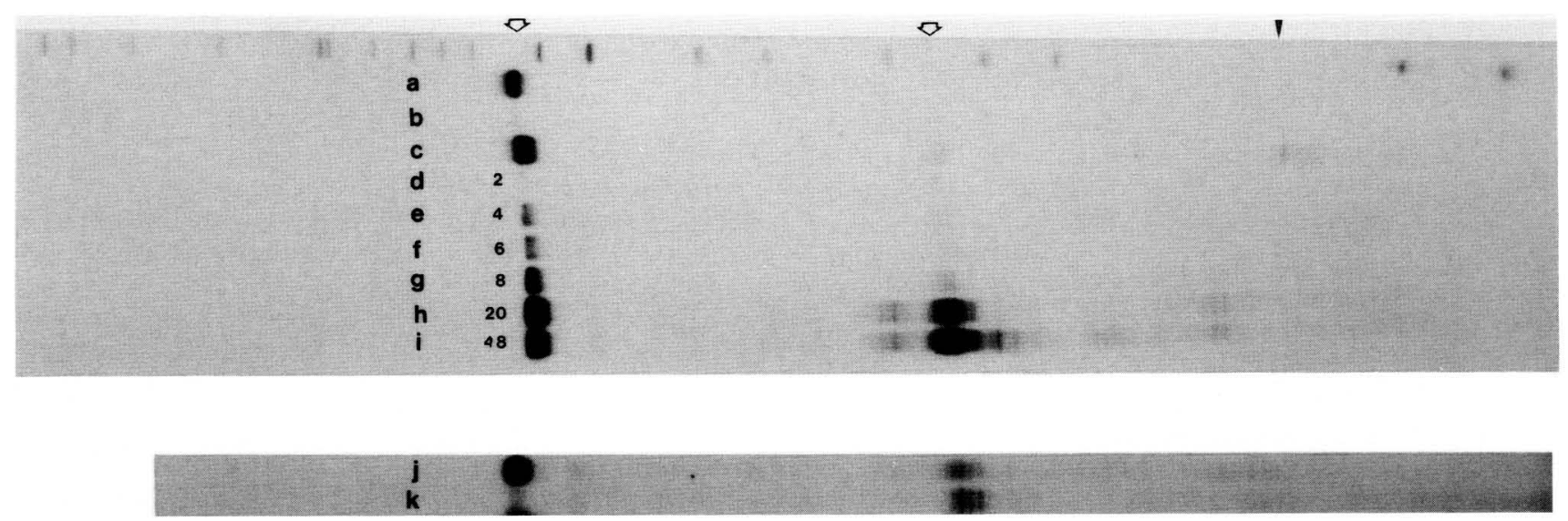

Figure 5. Time course and stability of some of the $3^{\prime}$ ends of SV40 late RNA in oocytes. Oocytes were injected with SV40 DNA and incubated for $2(d), 4(e), 6(f), 8(g), 20(h)$, and $48(i)$ hr. Following RNA extraction, samples were hybridized to the $3^{\prime}$ NcoI probe used in Fig. 3, treated with S1 nuclease, and analyzed on a 5\% polyacrylamide-urea gel. Uninjected oocytes RNA $(b)$ and infected cell RNA (c) were analyzed as well. One-twentieth the amount of probe used in analysis is shown $a$. After an initial 6-hr incubation period $(f, j)$, oocytes were injected with $\alpha$-amanitin $(\sim 0.1 \mu \mathrm{g} / \mathrm{ml})$ and incubated for an additional 6-hr period $(k)$. Molecular-weight markers $(\mathrm{m})$ are the fragments generated by the HpaII cleavage of pBR322, described in the legend to Fig. 1 . 
DNA I, and the injected oocytes were incubated for $48 \mathrm{hr}$, and then cytoplasm and nuclei were separated by manual dissection. Cytoplasmic and nuclear fractions were transferred immediately to a tube containing RNA extraction buffer that included proteinase $\mathrm{K}$ (described in RNA preparation, below).

\section{RNA preparation}

Groups of 20 oocytes were solubilized in $0.2 \mathrm{ml}$ of buffer containing $10 \mathrm{~mm}$ Tris- $\mathrm{HCl}(\mathrm{pH} 7.5), 10 \mathrm{mM} \mathrm{NaCl}, 1 \mathrm{~mm} \mathrm{MgCl}{ }_{2}$ $2 \%$ SDS, and $1 \mathrm{mg} / \mathrm{ml}$ proteinase $\mathrm{K}$. Samples were incubated at room temperature for $30 \mathrm{~min}$, extracted with phenol, chloroform, and isoamyl alcohol, and then ethanol-precipitated. DNase I digestion of RNA preparations was carried out in 200 $\mu \mathrm{l}$ of buffer containing $5 \mathrm{mM} \mathrm{MgCl}, 1.5 \mathrm{~mm}$ dithiothreitol (DTT), $1 \mathrm{mg} / \mathrm{ml}$ DNase I, and 100 units of RNasin. Samples were incubated at $37^{\circ} \mathrm{C}$ for $15 \mathrm{~min}$ followed by phenol, chloroform, and isoamylalcohol extraction, and then ethanol-precipitation.

\section{S1 nuclease mapping}

S1 nuclease mapping was performed by the method of Berk and Sharp (1978), as modified by Weaver and Weissmann (1979). To map the 5' ends of the late RNA, a single-stranded HpaII-TaqI fragment was used. For this purpose, SV40 DNA was cleaved with HpaII and TaqI, treated with calf intestinal phosphatase, and labeled with $\left[\alpha^{-32} \mathrm{P}\right] \mathrm{ATP}$ and T4 polynucleotide kinase to a sp. act. of $>10^{7} \mathrm{cpm} / \mu \mathrm{g}$. Following labeling, the HpaII-TaqI fragment was denatured, and the DNA strands separated on a $4 \%$ polyacrylamide gel. Typically, RNA of 0.4 oocyte equivalent was used with $20 \mathrm{ng}$ DNA probe. Hybridization was carried out for $6 \mathrm{hr}$ at $37^{\circ} \mathrm{C}$ in buffer containing $50 \%$ formamide, 0.4 $\mathrm{mM} \mathrm{NaCl}, 0.04 \mathrm{~mm}$ piperazine- $N, N^{\prime}$-bis[2-ethane-sulfonic acid] (pH 6.5), and $1 \mathrm{~mm}$ EDTA and was followed by digestion with S1 nuclease $(4000 \mathrm{U} / \mathrm{ml})$ for $30 \mathrm{~min}$ at $37^{\circ} \mathrm{C}$. Prior to incubation at the hybridization temperature, nucleic acids were denatured at $80^{\circ} \mathrm{C}$ for $10 \mathrm{~min}$ in the above buffer. $\mathrm{S} 1$ nuclease-resistant fragments were resolved on a polyacrylamide-urea gel.

To map the 3' and 5' ends of the small RNA species, three 3'labeled fragments were used. $\mathrm{NcoI}-\mathrm{HpaI}$ (spanning nucleotides 333-499), the BanI-HpaI (spanning nucleotides 294-499), and DdeI-HpaI (spanning nucleotides 287-499) fragments were labeled with $\alpha^{-32} \mathrm{P}$-labeled deoxynucleotides, using the large fragment of DNA polymerase I. S1 analysis was performed as described above, except that hybridization was carried out at $50^{\circ} \mathrm{C}$ in $80 \%$ formamide and was followed by nuclease S1 digestion at $45^{\circ} \mathrm{C}$. The protected fragments were separated on a $5 \%$ polyacrylamide-urea gel.

\section{Immunoprecipitation of capped RNAs}

Capped RNAs were immunoprecipitated with affinity-purified antibodies raised against 2,2,7-trimethylguanosine $\left(\mathrm{m}_{3} \mathrm{G}\right)$ (Bringman et al. 1983). RNA of 0.1 oocyte equivalent was immunoprecipitated with $50 \mu \mathrm{g}$ of the anti- $\mathrm{Me}^{7} \mathrm{G}$ antibodies, using a modification of the methods described by Bringmann et al. (1983) and DeRobertis et al. (1982). Briefly, anti-Me ${ }^{7} \mathrm{G}$ antibodies were bound to protein A-Sepharose beads that were coated previously with goat anti-mouse IgG. RNA was incubated with the antibody protein A-Sepharose complex for $1 \mathrm{hr}$ at $4^{\circ} \mathrm{C}$ in NET-2 buffer $(50 \mathrm{~mm}$ Tris- $\mathrm{HCl}$ at $\mathrm{pH} 7.5,150 \mathrm{~mm}$ $\mathrm{NaCl}, 0.05 \%$ Nonidet P-40/ that contained $2 \mathrm{~mm}$ DTT and 1 unit/ $\mu$ l RNasin. Following four washes with NET- 2 buffer, the bound and unbound RNA fractions were treated with pro- teinase $\mathrm{K}$, phenol, and chloroform and were isoamylalcohol-extracted and ethanol-precipitated.

\section{Northern analysis}

RNAs were separated on either $5 \%$ or $8 \%$ polyacrylamide-urea gels and transferred electrophoretically to a GeneScreen Plus membrane. The blot was hybridized as described (Zeitlin and Efstratiadis 1984) to a ${ }^{32} \mathrm{P}-$ labeled KpnI-HpaI SV40 DNA fragment (nucleotides 294-499).

\section{Debranching analysis}

Debranching reactions were carried out essentially as described by Noble et al. (1987). RNA purified from $0.7-1.0$ oocytes was mixed with $0.1 \mathrm{ng}$ of ${ }^{32} \mathrm{P}$-labeled SV40 large $\mathrm{T}$ antigen lariat isolated from $5 \%$ urea-polyacrylamide gels after in vitro splicing reactions (Noble et al. 1987). This was added to reaction mixtures containing $5 \mu \mathrm{l} \mathrm{HeLa} \mathrm{S-100} \mathrm{extract} \mathrm{(Ruskin} \mathrm{and}$ Green 1985), $20 \mathrm{~mm}$ HEPES (pH 7.9), $20 \mathrm{~mm} \mathrm{KCl,} 10 \mathrm{~mm}$ EDTA, $20 \%$ glycerol, and $1 \mathrm{mM}$ DTT in a final volume of $25 \mu \mathrm{l}$. After incubation for $1 \mathrm{hr}$ at $30^{\circ} \mathrm{C}$, an additional 5- $\mu$ l aliquot of HeLa S-100 was added, and the incubation continued for an additional hour. RNA was purified from the debranching reactions by phenol-chloroform extraction and ethanol precipitation and subjected to Northern analysis as described above.

\section{Acknowledgments}

We thank J. Noble for providing purified SV40 large $T$ intron and L. Ryner for preparing the S-100 extract used for the debranching reactions. J. Manley and J. Mertz are acknowledged for their critical reading of this manuscript. This work was supported by National Institutes of Health grant CA-33620 and National Science Foundation grant PCM-82-16798.

\section{References}

Alwine, J.C. 1982. Hybrid selection of small RNAs by using SV40 DNA: Evidence that the SV40 associated small RNA is synthesized by specific cleavage from large viral transcripts. J. Virol. 43: 987-996.

Arenas, J. and J. Hurwitz. 1987. Purification of a RNA debranching activity from HeLa cells. I. Biol. Chem. 262: 4274-4279.

Berk, A.J. and P.A. Sharp. 1978. Spliced early mRNA of simian virus 40. Proc. Nat1. Acad. Sci. 75: 1274-1278.

Bringman, P., R. Reuter, J. Rinke, B. Appel, R. Bald, and R. Luhrmann. 1983. 5' terminal caps of snRNAs are accessible for reaction with $\mathrm{m}_{3}^{2.2 .7}$ G-specific antibody in intact snRNPs. J. Biol. Chem. 258: 2745-2747.

Coleclough, C. and D. Wood. 1984. Introns excised from immunoglobin pre-mRNAs exist as discrete species. Mol. Cell. Biol. 4: 2017-2022.

DeRobertis, E.M. and J.E. Mertz. 1977. Coupled transcription translation of DNA injected into Xenopus oocytes. Cell 12: $175-182$.

DeRobertis, E.M., S. Lienhard, and R. Parisot. 1982. Intracellular transport of microinjected $5 \mathrm{~S}$ and small nuclear RNAs. Nature 295: 572-577.

Domdey, H., B. Apostol, R.J. Lin, A. Neuman, E. Brody, and J. Abelson. 1984. Lariat structures are in vivo intermediates in yeast pre-mRNA splicing. Cell 39: 611-621.

Fradin, A., R. Jove, C. Hemenway, H.D. Keiser, J.L. Manley, and C. Prives. 1984. Splicing pathways of SV40 mRNAs in 
Xenopus laevis oocytes differ in their requirements for snRNPs. Cell 37: 927-936.

Fradin, A., J.L. Manley, and C. Prives. 1982. Methylation of simian virus $40 \mathrm{HpaII}$ site affects late, but not early, viral gene expression. Proc. Natl. Acad. Sci. 79: 5142-5146.

Fried, M. and C. Prives. 1986. The biology of simian virus 40 and polyomavirus. Cancer Cells 4: 1-16.

Ghosh, P.K., V.B. Reddy, J. Swinscoe, P. Lebowitz, and S.M. Weissman. 1978. The heterogeneity and 5 ' terminal structures of the late RNAs of simian virus 40 . I. Mol. Biol. 126: $813-825$.

Gidoni, D., C. Kahana, D. Canaani, and Y. Groner. 1981. Specific in vitro initiation of transcription of simian virus 40 early and late genes occurs at the various cap nucleotides including cytidine. Proc. Natl. Acad. Sci. 78: 2174-2178.

Grabowski, P., R.A. Padgett, and P.A. Sharp. 1984. Messenger RNA splicing in vitro: An excised intervening sequence and a potential intermediate. Cell 37: 415-427.

Graessman, A., M. Graessman, G. Guhl, and C. Muller. 1978. Quantitative correlation between simian virus $40 \mathrm{~T}$-antigen synthesis and late viral gene expression in permissive and nonpermissive cells. I. Cell Biol. 77: 1-8.

Hay, N., D.H. Skolnik, and Y. Aloni. 1982. Attenuation in the control of SV40 gene expression. Cell 29: 183-193.

Kramer, A. and W. Keller. 1985. Purification of a protein required for the splicing of pre-mRNA and its separation from the lariat debranching enzyme. EMBO I. 4: 3571-3581.

Lebowitz, P. and S.M. Weissman. 1979. Organization and transcription of the simian virus 40 genome. Curr. Top. Microbiol. Immunol. 87: 43-172.

Lerner, M.R. and J.A. Steitz. 1979. Antibodies to small nuclear RNAs complexed with proteins are produced by patients with systemic lupus erythematosus. Proc. Natl. Acad. Sci. 76: 5495-5499.

Mertz, J.E. and J.B. Gurdon. 1977. Purified DNAs are transcribed after microinjection into Xenopus oocytes. Proc. Natl. Acad. Sci. 74: 1502-1506.

Michaeli, T. and C. Prives. 1985. Regulation of simian virus 40 gene expression Xenopus laevis oocytes. Mol. Cell. Biol. 5: $2019-2028$.

Michaeli, T. and C. Prives. 1987. pBR322 DNA inhibits simian virus 40 gene expression in Xenopus laevis oocytes. Nucleic Acids Res. 15: 1579-1594.

Miller, T.J., D.L. Stephens, and J.E. Mertz. 1982. Kinetics of accumulation and processing of simian virus 40 RNA in Xenopus laevis oocytes microinjected with simian virus 40 DNA. Mol. Cell. Biol. 2: 1581-1594.

Noble, J.C.S., Z.-Q. Pan, C. Prives, and J.L. Manley. 1987. Splicing of early pre-mRNA to large $\mathrm{T}$ and small $\mathrm{t}$ mRNAs utilizes different patterns of lariat branch sites. Cell 50: $227-236$.

Reddy, V.B., P.K. Ghosh, P. Lebowitz, and S.M. Weissman. 1978. Gaps and duplicated sequences in the leaders of SV40 16S RNA. Nucleic Acids Res. 5: 4195-4214.

Rodriguez, J.R., C.W. Pikielny, and M. Robash. 1984. In vivo characterization of yeast mRNA processing intermediates. Cell 39: 603-610.

Rungger, D. and H. Turler. 1978. DNAs of simian virus 40 and polyoma direct the synthesis of viral tumor antigens and capsid proteins in Xenopus oocytes. Proc. Natl. Acad. Sci. 75: 6073-6077.

Ruskin, B., A.R. Krainer, T Maniatis, and M.R. Green. 1984. Excision of an intact intron as a novel lariat structure during pre-mRNA splicing in vitro. Cell 38: 317-331.

Ruskin, B. and M.R. Green. 1985. An RNA processing activity that debranches RNA lariats. Science 229: 135-140.
Tooze, J. 1981. DNA tumor viruses, 2nd ed. Cold Spring Harbor Laboratory, Cold Spring Harbor, New York.

Wallace, J.C. and M. Edmonds. 1983. Polyadenylated nuclear RNA contains branches. Proc. Natl. Acad. Sci. 80: 950-954.

Weaver, R.F. and C. Weissmann. 1979. Mapping of RNA by a modification of the Berk-Sharp procedure: The $5^{\prime}$ termini of $15 \mathrm{~S} \beta$-globin mRNA precursor and mature $10 \mathrm{~S} \beta$-globin mRNA have identical map coordinates. Nucleic Acids Res. 7: 1175-1193.

Wickens, M.P. and J.B. Gurdon. 1983. Post-transcriptional processing of simian virus 40 late transcripts in injected frog oocytes. J. Mol. Biol. 163: 1-26.

Zeitlin, S. and A. Efstratiadis. 1984. In vivo splicing products of the rabbit $\beta$-globin pre-mRNA. Cell 39: 589-612. 


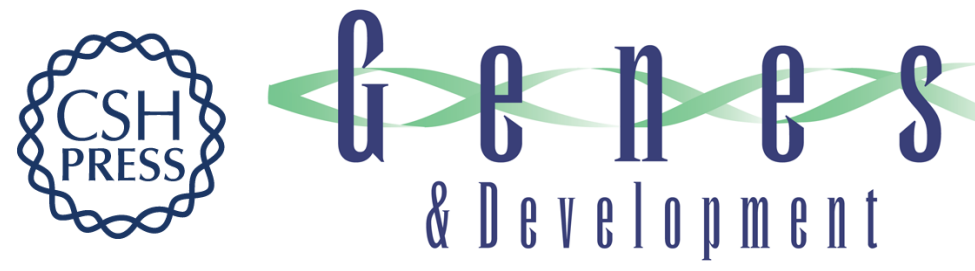

\section{An excised SV40 intron accumulates and is stable in Xenopus laevis oocytes.}

T Michaeli, Z Q Pan and C Prives

Genes Dev. 1988, 2:

Access the most recent version at doi:10.1101/gad.2.8.1012

References This article cites 33 articles, 15 of which can be accessed free at:

http://genesdev.cshlp.org/content/2/8/1012.full.html\#ref-list-1

License

Email Alerting

Service

Receive free email alerts when new articles cite this article - sign up in the box at the top right corner of the article or click here.

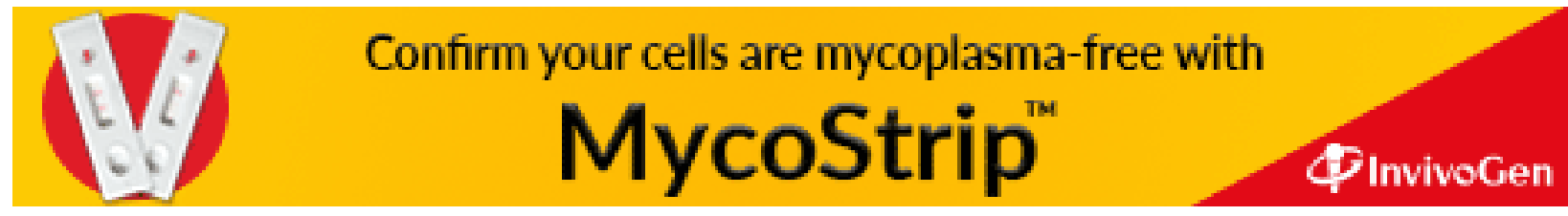

